$$
\begin{aligned}
& \text { KEK-P } 93-169 \\
& \text { Scu } 9409
\end{aligned}
$$

KEK Preprint 93-169

December 1993

H

\title{
New Insulator Film of Integrated Capacitor for a Silicon Strip Detetor
}

S. OKUNO, H. IKEDA, T. AKAMINE, Y. SAITOH, K. KADOI and Y. KOJIMA

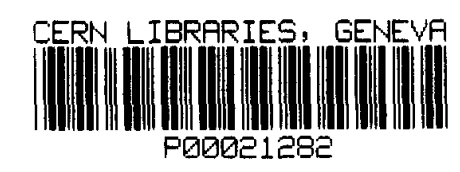

Submitted to the IEEE Transaction on Nucl. Sci. Symposium, November 2 - 6, 1993, San Francisco, California, U.S.A. 
National Laboratory for High Energy Physics, 1993

KEK Reports are available from:

Technical Information \& Library

National Laboratory for High Energy Physics

1-1 Oho, Tsukuba-shi

Ibaraki-ken, 305

JAPAN

Phone: $\quad 0298-64-1171$

Telex: $\quad 3652-534$ (Domestic)

(0)3652-534 (International)

Fax: $\quad$ 0298-64-4604

Cable: $\quad$ KEK OHO

E-mail: LIBRARY@JPNKEKVX (Bitnet Address)

library@kekvax.kek.jp (Internet Address) 


\title{
New Insulator Film of Integrated Capacitor for a Silicon Strip Detector
}

\author{
S. Okuno and H. Ikeda \\ Department of Accelerator Science, The Graduate University for Advanced Studies, \\ National Laboratory for High Energy Physics, 1-1 Oho, Tsukuba-shi, Ibaraki 305, Japan \\ T. Akamine, Y. Saitoh, K. Kadoi and Y. Kojima \\ Seiko Instruments Inc., 563, Takatuka-shinden, Matsudo-shi, Chiba 271, Japan
}

\begin{abstract}
New stacked thick insulator films have been developed to be applied for a silicon strip detector. We expected that the stacked films were superior integrated capacitors in terms of the high electric breakdown voltage, long-term reliability, large unit capacitance and radiation hardness. We measured the electrical behaviors of test capacitors with single-layer silicon dioxide $\left(\mathrm{SiO}_{2}\right)$, single-layer silicon nitride $\left(\mathrm{Si}_{3} \mathrm{~N}_{4}\right)$, NO (silicon Nitride - silicon diOxide), ON (silicon diOxide - silicon Nitride) and ONO (silicon diOxide - silicon Nitride - silicon diOxide) capacitors.
\end{abstract}

\section{INTRODUCTION}

The DSSDs (Double-sided Silicon Strip Detectors) for the KEK B-factory [1] employ an integrated capacitor in order to get away from saturation for a preamplifier which should be isolated from the d.c. bias of the detector. The bias voltage for obtaining a full depletion in the detector is approximately $100 \mathrm{~V}$. The capacitor is stressed in a part or all of the bias voltage. The integrated capacitor should meet following requirements:

- The breakdown voltage should be sufficiently high.

- The TDDB (Time Dependent Dielectric Breakdown) property should be sufficiently long for using a longtime operation of silicon strip detectors.

- The leakage current through the insulator should be sufficiently small.

- In order to obtain a large charge collection efficiency, the capacitance is as large as possible compared to the inter-strip capacitance or the pn-junction capacitance.

In order to satisfy these conditions, a stacked insulator film, ON, NO or ONO insulator film [2][3], was chosen for an integrated capacitor. Since the dielectric constant of $\mathrm{Si}_{3} \mathrm{~N}_{4}(7.4)$ is larger than that of $\mathrm{SiO}_{2}(3.9)$, the capacitance of $\mathrm{Si}_{3} \mathrm{~N}_{4}$ is larger than that of $\mathrm{SiO}_{2}$. The leakage current in $\mathrm{Si}_{3} \mathrm{~N}_{4}$ is generally said to be larger than $\mathrm{SiO}_{2}$. In order to include the advantages of each, we made stacked insulators. The stacked insulators are expected to have superior properties: a high breakdown voltage, long-term reliability, large unit capacitance and radiation hardness. $\mathrm{A} \mathrm{SiO}_{2}$ insulator and $\mathrm{a} \mathrm{Si}_{3} \mathrm{~N}_{4}$ insulator have different current transport mechanisms; the current in the $\mathrm{SiO}_{2}$ flows by FowlerNordheim emission [4][5] and the current in the $\mathrm{Si}_{3} \mathrm{~N}_{4}$ flows by Poole-Frenkel emission [6]. The Fowler-Nordheim emission is according to electron tunneling through the $\mathrm{SiO}_{2}$ and the Poole - Frenkel emission is dominated by the so-called internal Schottky emission in the $\mathrm{Si}_{3} \mathrm{~N}_{4}$. Since the $\mathrm{SiO}_{2}$ insulator limits injected electrons from the electrode to the $\mathrm{Si}_{3} \mathrm{~N}_{4}$ insulator, we can expect less leakage current using the stacked insulator. The stacked insulator using different materials compensates for any weak spots of each other. The technology of the stacked insulators has been studied for only thin films which are used for VLSI DRAM and EEPROM devices so far, but have not been studied for thick films $(200 \AA \sim 2000 \AA)$. Since traps on the interface between $\mathrm{SiO}_{2}$ and $\mathrm{Si}_{3} \mathrm{~N}_{4}$ work as recombination centers for radiation-originated carriers, the structure of stacked layers of $\mathrm{SiO}_{2}$ and $\mathrm{Si}_{3} \mathrm{~N}_{4}$ has a good chance to obtaining properties of radiation hardness; however, the radiation hardness properties are not discussed.

In section II we describe the fabrication procedures of the test samples. In section III we explain the experimental procedures and their results and then consider the results. In section IV we conclude the results and discuss future study plans.

\section{FABRICATION OF TEST Elements}

In order to neglect the voltage drop through a silicon substrate, we used silicon substrates which had bulk resistivity of $5 \sim 7 \Omega \cdot \mathrm{cm}$. The silicon substrate was $n$-type silicon, $525 \mu \mathrm{m}$ thick, $\langle 100\rangle$ oriented and polished to a mirror finish. The $\mathrm{SiO}_{2}$ on the substrate and the $\mathrm{SiO}_{2}$ on the $\mathrm{Si}_{3} \mathrm{~N}_{4}$ are called bottom $\mathrm{SiO}_{2}$ and top $\mathrm{SiO}_{2}$, respectively. Figure 1 shows the structure of a capacitor using ONO insulator, which is three layers of stacked dielectric material, bottom $\mathrm{SiO}_{2}, \mathrm{Si}_{3} \mathrm{~N}_{4}$ and top $\mathrm{SiO}_{2}$. 


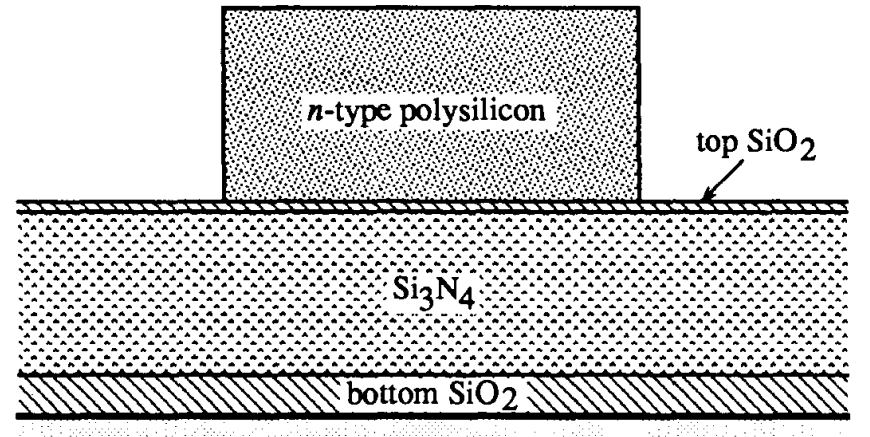

n-type silicon
Table 1: Table of test samples.

\begin{tabular}{rrrr}
\hline & bottom $\mathrm{SiO}_{2}$ & $\mathrm{Si}_{3} \mathrm{~N}_{4}$ & top $\mathrm{SiO}_{2}$ \\
\hline $\mathrm{SiO}_{2}$ & $440 \AA$ & - & - \\
& $1630 \AA$ & - & - \\
$\mathrm{Si}_{3} \mathrm{~N}_{4}$ & - & $390 \AA$ & - \\
& - & $1640 \AA$ & - \\
$\mathrm{ON}$ & $440 \AA$ & $1640 \AA$ & \\
$\mathrm{NO}(\mathrm{Th}$ rermal) & $440 \AA$ & $1640 \AA$ & $<20 \AA$ \\
$\mathrm{ONO}$ (Thermal) & $440 \AA$ & $1640 \AA$ & $<20 \AA$ \\
ONO(HTO) & $440 \AA$ & $1640 \AA$ & $100 \AA$ \\
\hline
\end{tabular}

Thermal means to be covered with the top $\mathrm{SiO}_{2}$ of the thermal $\mathrm{SiO}_{2}$ on the $\mathrm{Si}_{3} \mathrm{~N}_{4}$. HTO is covered with the top $\mathrm{SiO}_{2}$ of the HTO.

Figure 1: Structure of a capacitor using the ONO insulator.

The typical thicknesses of insulators were measured by process technicians using an ellipsometer. Two kinds of thicknesses of the bottom $\mathrm{SiO}_{2}$ were made by a thermally grown process from the silicon substrate. The thickness of the bottom $\mathrm{SiO}_{2}$, which was thermally grown at $1000^{\circ} \mathrm{C}$ in dry $\mathrm{O}_{2}$ for $35 \mathrm{~min}$ (in wet $\mathrm{O}_{2}$ for $30 \mathrm{~min}$ ), was $440 \AA \pm 1.1 \AA$ $(1630 \AA \pm 3 \AA)$. Top $\mathrm{SiO}_{2}$ was also made by two methods: thermal $\mathrm{SiO}_{2}$ and HTO (High Temperature Oxide by CVD*). The thermal $\mathrm{SiO}_{2}$ was made by thermal growth at $1000^{\circ} \mathrm{C}$ in wet $\mathrm{O}_{2}$ for $72 \mathrm{~min}$ on $\mathrm{Si}_{3} \mathrm{~N}_{4}$. This condition was equivalent to forming $\mathrm{SiO}_{2}$ of $4360 \AA \pm 8 \AA$ on a silicon substrate, which was a part of a process monitor element. We could not measure the thickness of the thermal $\mathrm{SiO}_{2}$ upon $\mathrm{Si}_{3} \mathrm{~N}_{4}$. We could estimate that its thickness was extremely thinner than $20 \AA$, since no differences in the capacitance were observed between an ONO capacitor with top $\mathrm{SiO}_{2}$ of thermal $\mathrm{SiO}_{2}$ and an ON capacitor without top $\mathrm{SiO}_{2}$. The HTO was made of $\mathrm{SiO}_{2}$ deposition by the process of reaction of dichlorosilan $\left(\mathrm{SiH}_{2} \mathrm{Cl}_{2}\right)$ at a gas flow rate $50 \mathrm{sccm}{ }^{\dagger}$ and nitrous oxide $\left(\mathrm{N}_{2} \mathrm{O}\right)$ with $500 \mathrm{sccm}$ at a temperature of $850^{\circ} \mathrm{C}$ and a pressure of $60 \mathrm{~Pa}$ for 4 min $25 \mathrm{sec}$. The thickness of the HTO for the top $\mathrm{SiO}_{2}$ was $100 \AA \pm 2 \AA$. The thicknesses of $\mathrm{Si}_{3} \mathrm{~N}_{4}$ insulators were $390 \AA \pm 3 \AA$ and $1640 \AA \pm 11 \AA$ by the process of reacting dichlorosilan at a gas flow rate of $70 \mathrm{sccm}$ and ammonia $\left(\mathrm{NH}_{3}\right)$ with $700 \mathrm{sccm}$ at a temperature of $740^{\circ} \mathrm{C}$ at a pressure of $95 \mathrm{~Pa}$ for $13 \mathrm{~min}$ and $44 \mathrm{~min}$, respectively. This process is called LPCVD (Low Pressure Chemical Vapor Deposition). Table 1 lists the configuration of test capacitors. We prepared two samples of single-layer $\mathrm{SiO}_{2}$, two samples of single-layer $\mathrm{Si}_{3} \mathrm{~N}_{4}$, one sample of an ON stacked insulator, one sample of a $\mathrm{NO}$ (Thermal) stacked insulator and two samples of an ONO stacked insulator. After the insulators were made on the substrate, polysilicon was deposited on the insulator to define the capacitor area and on

* CVD stands for Chemical Vapor Deposition

${ }^{\dagger} \mathrm{sccm}$ stands for Standard Cubic Centimeters per Minutes. the backside of the substrate to provide a backside contact. The polysilicon was doped by phosphorus. The patterns of the capacitors were formed by standard photoresist techniques. The capacitors were shaped as circular disk with radii of $125,250,500$ and $1004 \mu \mathrm{m}$.

\section{EXPERIMENTS AND DISCUSSION}

All measurements were made at room temperature. Figure 2 shows a schematic diagram of the setup for the electrical measurements.

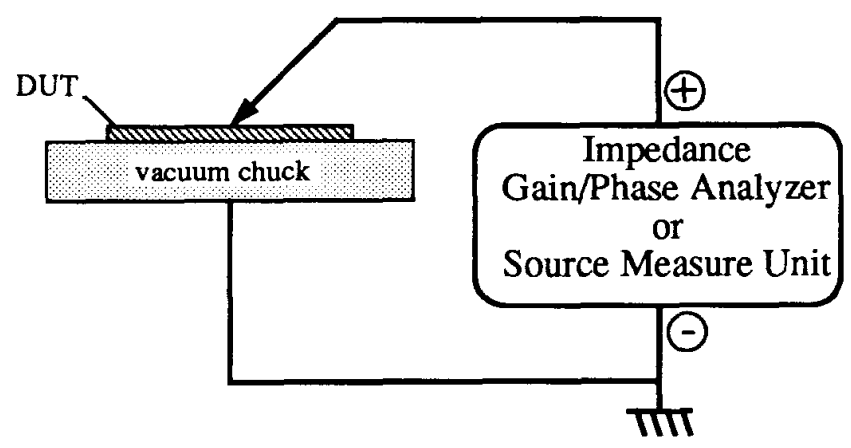

Figure 2: Experimental setup. DUT stands for Device Under Test.

\section{A. Capacitance}

Capacitance measurements for the capacitors were made using a HP4194A Impedance/Gain-Phase Analyzer. The measurement frequency was $10 \mathrm{kHz}$ and the amplitude for the a.c. frequency was $500 \mathrm{mV}$. We determined the unit capacitance by taking an average over four capacitors $(r=125 \mu m$ to $1004 \mu m)$. The measurement accuracy was about $\pm 2 n F / \mathrm{cm}^{2}$.

Figure 3 shows the unit capacitance of the capacitors using the $\mathrm{SiO}_{2}, \mathrm{Si}_{3} \mathrm{~N}_{4}$ and $\mathrm{ONO}$ (Thermal) insulators. The solid, dotted and dashed lines are the theoretical values 


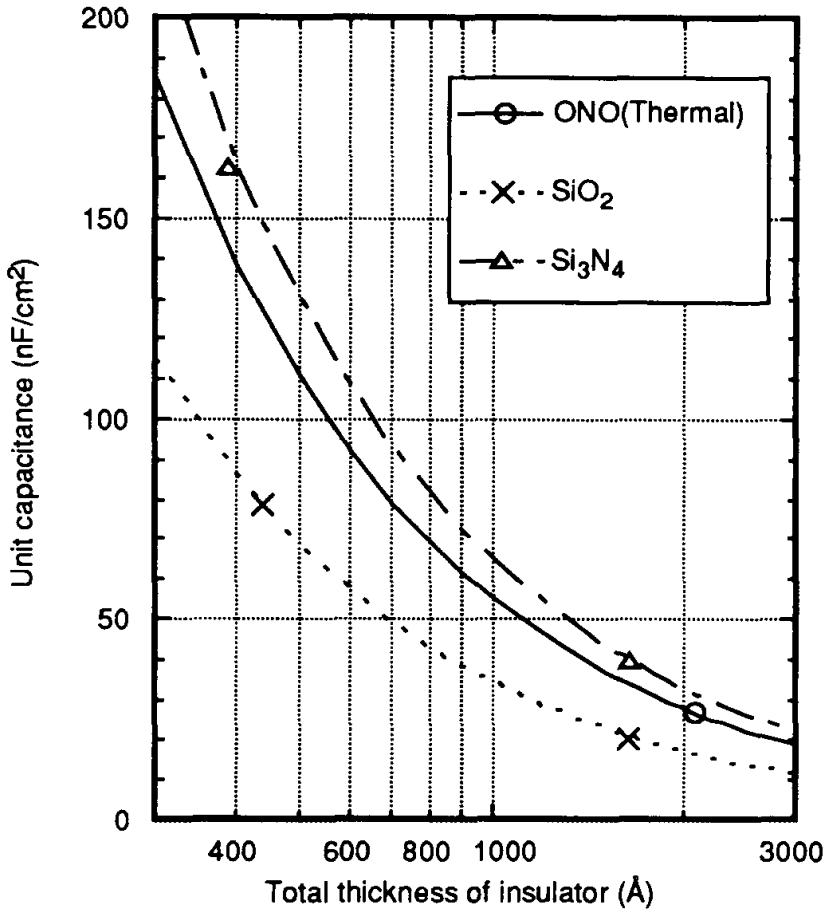

Figure 3: Unit Capacitance of single-layer $\mathrm{SiO}_{2}$, singlelayer $\mathrm{Si}_{3} \mathrm{~N}_{4}$ and $\mathrm{ONO}$ (Thermal).

for the unit capacitances of the ONO(Thermal), the $\mathrm{SiO}_{2}$ and the $\mathrm{Si}_{3} \mathrm{~N}_{4}$, respectively. The measured capacitances were consistent with the thicknesses measured with an ellipsometer.

The unit capacitance of the ONO(Thermal) was approximately 1.7-times larger than the capacitance of singlelayer $\mathrm{SiO}_{2}$. The unit capacitance depended only on the thickness and the combination ratio of $\mathrm{SiO}_{2}$ and $\mathrm{Si}_{3} \mathrm{~N}_{4}$.

\section{B. Current Transport}

We applied bias voltages and measured the current with a Keithley Model 237 high voltage source measure unit. A positive voltage was applied from a polysilicon gate electrode on an insulator. Since we used $n$-type silicon substrate, current does not flow in an insulator for a negative bias voltage due to the development of a depletion region in the silicon substrate. We, therefore, could observe electron injection from the silicon substrate and/or hole injection from the polysilicon gate electrode. The applied voltages were swept with a step of about $0.5 \mathrm{MV} / \mathrm{cm}$ on the average electric field. The average electric field was derived from the applied voltage divided by the total geometrical thickness of the insulators. Since we filled up the traps in the insulators for each voltage step, it took $100 \sim 20000 \mathrm{sec}$ before the current reached a steady state condition, i.e. $\frac{\Delta I}{I} \leq 0.05 \% / \mathrm{sec}$, or the current decreased below the measurement limit, i.e. $I \leq 10^{-13} \mathrm{~A}$.

Table 2 shows the electric breakdown properties for an
Table 2: Breakdown properties.

\begin{tabular}{rrrrr}
\hline & \multicolumn{3}{c}{ Electric field } & \multicolumn{2}{c}{$\begin{array}{c}\text { Electric } \\
\text { flux density }\end{array}$} \\
& $\bar{E}$ & $\mathrm{SiO}_{2}$ & $\mathrm{Si}_{3} \mathrm{~N}_{4}$ & (coulomb/cm $)$ \\
\hline $\mathrm{SiO}_{2}(1630 \AA)$ & 7.5 & 7.5 & - & $2.6 \times 10^{-6}$ \\
$\mathrm{Si}_{3} \mathrm{~N}_{4}(1640 \AA)$ & 8.0 & - & 8.0 & $5.2 \times 10^{-6}$ \\
ON & 9.0 & 14.4 & 7.6 & $5.0 \times 10^{-6}$ \\
$\mathrm{NO}(\mathrm{Thermal})$ & 8.9 & 16.7 & 8.8 & $5.8 \times 10^{-6}$ \\
ONO(Thermal) & 8.0 & 12.8 & 6.7 & $4.4 \times 10^{-6}$ \\
ONO(HTO) & 8.0 & 12.5 & 6.6 & $4.3 \times 10^{-6}$ \\
\hline
\end{tabular}

$\bar{E}$ means the average electric field.

average electric field $(\bar{E})$, electric field on $\mathrm{SiO}_{2}$, electric field on $\mathrm{Si}_{3} \mathrm{~N}_{4}$ and electric flux density. The electric flux density was estimated from the applied voltage, the geometrical thicknesses of the insulators and each dielectric constant, where we assumed no charge in the insulators and on the interface of the insulators. The breakdown properties included the effect of TDDB, since the stress time was very long, approximately over one day from the start of the sweep before a breakdown. The single-layer $\mathrm{SiO}_{2}$ had the smallest breakdown property for both $\bar{E}$ and the electric flux density. The NO(Thermal) had the highest breakdown property for the electric flux density. We have traditionally used typically a $2000 \AA \mathrm{SiO}_{2}$ insulator for the readout capacitor. When a voltage of $100 \mathrm{~V}$ was applied to the $2000 \AA \mathrm{SiO}_{2}$ insulator, the electric field on it was $5 \mathrm{MV} / \mathrm{cm}$. All test samples satisfied the minimum requirement of the electric breakdown voltage.

Figure 4 shows the current density versus the electric flux density of the $\mathrm{SiO}_{2}, \mathrm{Si}_{3} \mathrm{~N}_{4}, \mathrm{ON}$, NO(Thermal), ONO(Thermal) and ONO(HTO). The lower limit of the measurement was approximately $10^{-10} \mathrm{~A} / \mathrm{cm}^{2}$. At the last point of the plots, the insulators were broken. In order to discuss the performance of the insulator, i.e. low leakage current, high breakdown property and large unit capacitance, we chose the electric flux density for the lateral axis. This is because a larger electric flux density shows a larger unit capacitance and higher electric breakdown property. A good insulator, therefore, shows a lower current density and a higher electric flux density for breakdown.

The area of a readout capacitor on a silicon strip detector is typically $3.25 \times 10^{-3} \mathrm{~cm}^{2} / \mathrm{strip}$. In order to obtain a low noise level, we demand that the leakage current in the insulator is under $1 \mathrm{nA} / \mathrm{strip}$, i.e. $0.3 \mu \mathrm{A} / \mathrm{cm}^{2}$. The singlelayer $\mathrm{SiO}_{2}$ was the lowest electric flux density for breakdown and the highest current density. On the other hand, the NO(Thermal) insulator showed the highest electric flux density for breakdown and the least current density. The single-layer $\mathrm{Si}_{3} \mathrm{~N}_{4}$ showed the secondly highest electric fiux density for breakdown and the second least current density. The ONO(Thermal), ONO(HTO) and ON insulator showed almost the same property as each other.

The difference between the $\mathrm{Si}_{3} \mathrm{~N}_{4}$ and $\mathrm{NO}$ (Thermal) is the existence or nonexistence of top $\mathrm{SiO}_{2}$. The top $\mathrm{SiO}_{2}$ 


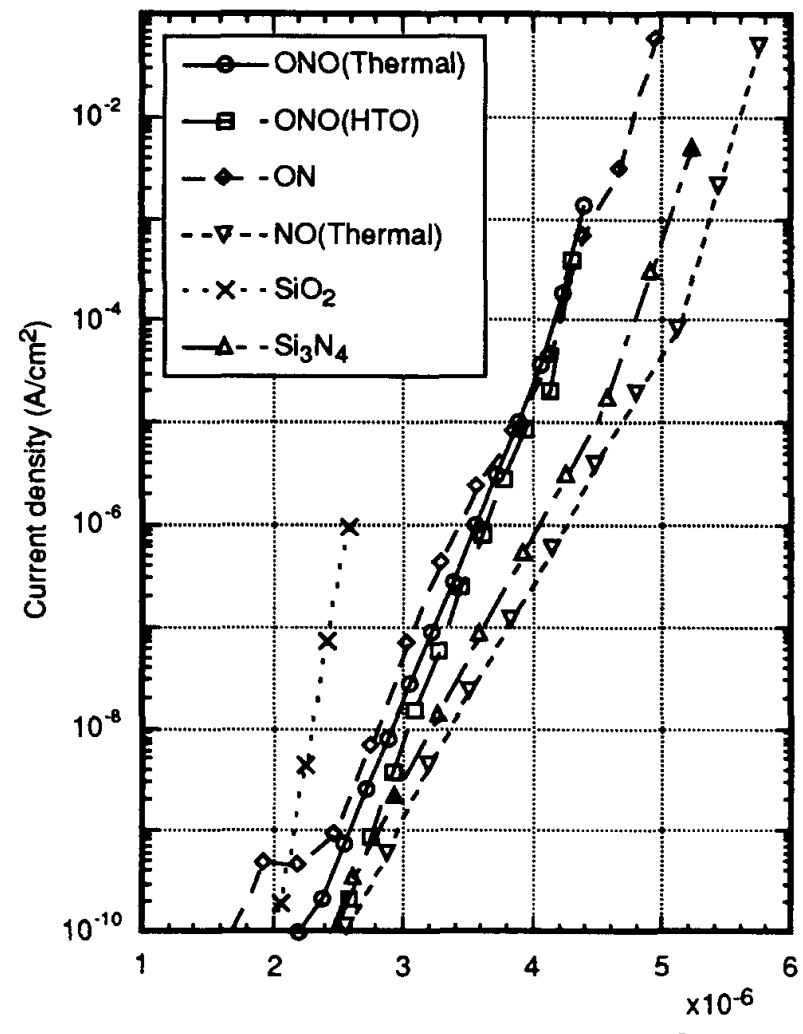

Electric flux density (coulomb/cm²)

Figure 4: Current density versus electric flux density

plays the role of a barrier for holes from the polysilicon electrode.

When we made the $\mathrm{Si}_{3} \mathrm{~N}_{4}$ layer onto the silicon substrate, we could assume that the surface of silicon was oxidized with thin natural $\mathrm{SiO}_{2}$, which played the role of bottom $\mathrm{SiO}_{2}$. We recognized that the single-layer $\mathrm{Si}_{3} \mathrm{~N}_{4}$ actually consisted of natural $\mathrm{SiO}_{2}$ and $\mathrm{Si}_{3} \mathrm{~N}_{4}$ in that order. The NO(Thermal) also accompanies natural $\mathrm{SiO}_{2}$ between silicon and $\mathrm{Si}_{3} \mathrm{~N}_{4}$. We can separate the data into two groups in terms of the thickness of the bottom insulator. One group has thin natural $\mathrm{SiO}_{2}$; another group has $440 \AA$ $\mathrm{SiO}_{2}$. The two groups property were clearly different. If electrons are injected into thick $\mathrm{SiO}_{2}$, the injected electrons are accelerated by the electric field for a long distance. The thicker $\mathrm{SiO}_{2}$ provides more energy for electrons. In thinner $\mathrm{SiO}_{2}$, electrons have less energy. In thick $\mathrm{SiO}_{2}$, the electrons have a good chance to excite another electron in the valence band to the conduction band. Thinner bottom $\mathrm{SiO}_{2}$, therefore, flows a smaller current transport. If we inject electrons from a polysilicon electrode, the top $\mathrm{SiO}_{2}$ probably decreases the current transport effectively.

\section{SUmmary}

This article provides the first data for thick stacked insulators, single-layer $\mathrm{SiO}_{2}$ and single-layer $\mathrm{Si}_{3} \mathrm{~N}_{4}$. We evaluated these insulators in terms of the capacitance and current transport. The unit capacitance of the ONO(Thermal) was approximately 1.7-times larger than the capacitance of single-layer $\mathrm{SiO}_{2}$. The unit capacitance depended on the thickness and the combination ratio of $\mathrm{SiO}_{2}$ and $\mathrm{Si}_{3} \mathrm{~N}_{4}$. We understood that the thinner $\mathrm{SiO}_{2}$ layer on the side of electron injection passed less current. We found that the stacked insulator was more useful than thick single-layer $\mathrm{SiO}_{2}$. We can temporarily conclude that the most useful insulator is the $\mathrm{NO}$ (Thermal) type, which is covered with a thin $\mathrm{SiO}_{2}$ on both sides of $\mathrm{Si}_{3} \mathrm{~N}_{4}$.

In a further study we will investigate the effect of the $\mathrm{SiO}_{2}$ thickness dependence on $\mathrm{Si}_{3} \mathrm{~N}_{4}$ for injected electrons. We will evaluate the side effect of the thermal oxidizing process on the $p n$-junction properties. The TDDB property will be checked, since we will use the detector for a long time. Radiation hardness will also be tested, since the detectors will be used under a radiation environment.

\section{ACKNOWLEDGEMENT}

The authors sincerely appreciate suggestions of the silicon micro-vertex detector group members, Y. Fujita, Y. Higashi, M. Ikeda, S. Koike, T. Matsuda, H. Ozaki, M. Tanaka, T. Tsuboyama, S. Avrillon, J. Haba, H. Hanai, S. Mori, K. Yusa and C. Fukunaga, and co-operation of J. Yamanaka, M. Kamiya and S. Miyahara, Seiko Instruments Inc. The directors of KEK, Profs. H. Sugawara, Y .Kimura, S. Iwata, and F. Takasaki are appreciated for their continuous encouragement.

\section{REFERENCES}

[1] C. Fukunaga et al., "Vertex Detector for KEK Bfactory", to be published in Nucl. Inst. \& Meth. or $K E K$ preprint $93-115$, Sep. 1993.

[2] Y. Ohji, T.Kusaka, I. Yoshida, A. Hiraiwa, K. Yagi, K. Mukai and O. Kasahara, "Reliability of Nano-meter Thick Multi-layer Dielectric Films on Poly-crystalline Silicon", Proceeding of IEEE/IRPS, (1987) 55-59.

[3] T. Watanabe, N. Goto, N. Yasuhisa, T. Yanase, T. Tanaka and S. Shinozaki, "High Reliability Trench Capacitor With $\mathrm{SiO}_{2} / \mathrm{Si}_{3} \mathrm{~N}_{4} / \mathrm{SiO}_{2}$ Stacked Film", Proceeding of IEEE/IRPS, (1987) 50-54.

[4] E. L. Murphy and R. H. Good, Jr, "Thermionic Emission, Field Emission, and the Transition Region", Phys. Rev., 102 (1956) 1464-1473.

[5] M. Lenzlinger and E. H. Snow, "Fowler-Nordheim Tunneling into Thermal Grown $\mathrm{SiO}_{2}$ ", J. Appl. Phys., 40 (1969) 278-283.

[6] S. M. Sze, "Current Transport and Maximum Dielectric Strength of Silicon Nitride Films", J. Appl. Phys., 38 (1967) 2951-2956. 

